\title{
Effect of Wet-dry Cycles on Disintegration Characteristics of Clay-bearing Sandstone with UF Cracks
}

\author{
Yu Wang ${ }^{1,2^{*}}$, Qingning Qiao', Jianlin $\mathrm{Li}^{1}$ \\ 1 Key Laboratory of Geological Hazards on Three Gorges Reservoir Area, Ministry of Education, China Three Gorges University, \\ Yichang City, Hubei Province, 443002, China \\ 2 Hubei Key Laboratory of Disaster Prevention and Mitigation, China Three Gorges University, Yichang City, Hubei Province, \\ 443002, China \\ * Corresponding author, e-mail: wangyu@ctgu.edu.cn
}

Received: 16 October 2019, Accepted: 14 December 2019, Published online: 10 February 2020

\begin{abstract}
UF cracks in rock masses commonly occur due to the unloading effect, which constantly happens after the variation of in-situ stress field or rock excavation. To study the effect of changes in moisture on rock samples with UF cracks, clay-bearing sandstone from the Triassic Badong group in the Three Gorges Reservoir Area were chosen and investigated. The rock samples with UF cracks are obtained by conducting triaxial unloading confining pressure experiment. The effect of wet-dry cycles on the UF cracks, morphology properties and microstructural features of the UF surface was investigated. The characteristics of particle-size uniformity from the sieve test were obtained by the calculation of RMS of particle contents. The test results show that UF cracks widen significantly and the disintegrated mass increases rapidly in the first three wet-dry cycles, while the fractal dimension of UF surface decreases sharply, but afterwards the disintegrated mass changes gently and the UF surface tends to be flat and smooth. Then, the RMS calculation of particle contents quantitatively evaluate the clay-bearing sandstone's disintegration properties, which indicate the particle uniformity plays a key role on its disintegration mechanism. Finally, we found that the microstructure of samples from FD group is looser and porous than those from SD group by SEM test. This investigation, considering the similar clay mineral content of all tested samples, demonstrates the closed link between the grain size distribution, microstructural features and the degree of disintegration.
\end{abstract}

\section{Keywords}

clay-bearing sandstone, UF cracks, wet-dry cycles, disintegration characteristics,

\section{Introduction}

As a typical failure phenomenon, unloading failure of rock mass often occurs during a long-term stage due to the variation of in-situ stress field [1] or in a fast way in the rock excavation of bank slopes, dam foundation or tunnels. In this failure process, lots of ruptured rock mass appear due to the unloading effect [2-6], which means various scales of cracks initiate, propagate and coalesce, from nano-level or micro-level to macro-level. In Three Gorges Reservoir Area of China, many rock-based engineering structures have to face the cyclic wet-dry conditions due to yearly rise and fall of reservoir water level between 145 and $175 \mathrm{~m}$ [7]. Therefore, it is also an important topic to study the effect of water-rock interaction on this kind of ruptured rock mass.

In recent years, a series of active exploration and research at home and abroad have been conducted on the influence of wet-dry cycles on rock deterioration or even disintegration [8-13]. Some scholars have found that the speed and degree of clay-bearing rocks disintegration are closely related to their clay contents [14], grain-size distribution [15-16] and microstructural features [17-19] as well. More importantly, it has been found that the deterioration of rock mechanical properties, such as attenuation of strength and the increase in deformation of rock masses which are caused by alternating action of wet and dry conditions are mainly from their original defects [20-22].

Therefore, in this research, for a better understanding of the effect of wet-dry cycle on ruptured rock masses, the clay-bearing sandstone samples from the Triassic Badong group in the Three Gorges Reservoir Area are selected to perform related tests. Firstly, triaxial unloading confining pressure tests are conducted to simulate the unloading failure and obtain the UF cracks. Then the disintegration tests 
are carried out with 9 wet-dry cycles to quantitatively analyze the deterioration law of clay-bearing sandstone and its disintegration mechanism under cyclic wet-dry conditions. During the tests, variations in UF cracks and morphology of the UF surface after undergoing different wet-dry cycles have been described and measured, and the characteristics of particle size distributions and microstructures of the clay-bearing sandstone are analyzed. On this basis, the deterioration characteristics and disintegration mechanism are discussed under the cyclic wet-dry conditions.

\section{Materials and methods}

\subsection{Sample material}

Clay-bearing sandstone were collected from the Three Gorges Reservoir Area for this research. To prepare rock samples for unloading confining pressure test, the samples were polished, cut and processed into cylinder with $50 \mathrm{~mm}$ in diameters and $100 \mathrm{~mm}$ in height according to the International Society for Rock Mechanics (ISRM 1981). Then, visual examination and ultrasonic testing of rock samples were performed and those with relatively weathered degree and wave velocity (Table 1) were selected as the experimental rock samples (Fig. 1). Under the help of $\mathrm{X}$-ray diffraction, the mineral component of tested samples is obtained and shown in Table 2, which indicates that the mineral component and content of different samples are also relatively close. By extension, three samples from the same group have been chosen to conduct uniaxial compression test, and the results of them are very consistent, so the average value of mechanical parameters are shown in Table 3. The effect of mechanical parameters on disintegration of rock mass has been widely discussed on the basis of laboratory tests [23-24]. As consequence a complete understanding of the effect of mechanical properties on disintegration of rock mass existed, which in turn provide the research foundation for this paper.

Table 1 P-wave velocity of tested samples (m/s)
\begin{tabular}{lccccccc}
\hline Sample.no & 2 & 10 & 62 & 13 & 52 & 56 \\
\hline P-wave velocity $(\mathrm{m} / \mathrm{s})$ & 1496 & 1697 & 1470 & 1593 & 1657 & 1534 \\
\hline
\end{tabular}

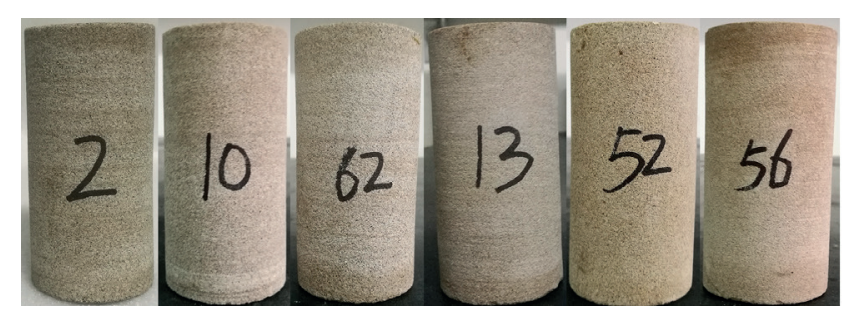

Fig. 1 Tested rock samples
Table 2 Mineral content of tested samples (\%)

\begin{tabular}{|c|c|c|c|c|c|c|c|}
\hline 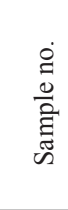 & 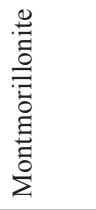 & $\stackrel{\mathscr{\Xi}}{\Xi}$ & : & $\stackrel{N}{\stackrel{\Xi}{\Xi}}$ & $\begin{array}{l}\overline{0} \\
0 \\
\frac{0}{0} \\
\overline{0} \\
1\end{array}$ & 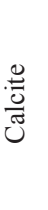 & $\frac{\stackrel{\Xi}{\Xi}}{\stackrel{0}{\Xi}}$ \\
\hline 2 & 10 & I & 1 & 57 & 10 & 18 & 6 \\
\hline 10 & 6 & / & 4 & 39 & 10 & 33 & 8 \\
\hline 62 & 12 & I & I & 46 & 9 & 25 & 8 \\
\hline 13 & 8 & / & 3 & 38 & 13 & 35 & 3 \\
\hline 52 & 8 & I & I & 39 & 31 & 19 & 3 \\
\hline 56 & 13 & 3 & 3 & 38 & 14 & 15 & 14 \\
\hline \multicolumn{8}{|c|}{ Table 3 Mechanical parameters of samples } \\
\hline \multicolumn{2}{|c|}{$\begin{array}{l}\text { Mechanical } \\
\text { parameters }\end{array}$} & \multicolumn{3}{|c|}{$\begin{array}{l}\text { Uniaxial } \\
\text { compressive } \\
\text { strength/MPa }\end{array}$} & $\begin{array}{l}\text { Elastic } \\
\text { modulus/GPa }\end{array}$ & & $\begin{array}{l}\text { Poisson's } \\
\text { ratio }\end{array}$ \\
\hline \multicolumn{2}{|c|}{ The average value } & \multicolumn{2}{|c|}{39.39} & \multicolumn{2}{|r|}{7.36} & \multicolumn{2}{|r|}{0.41} \\
\hline
\end{tabular}

\subsection{Experimental procedure}

In order to obtain samples with unloading failure cracks, we performed the unloading confining pressure test in the laboratory. The unloading point for the confining pressure in the triaxial unloading tests was set as $49 \mathrm{MPa}$, which is $70 \%$ of the triaxial strength, and the axial loading method was changed from displacement control to loading control at the unloading point, the initial confining pressures were $12 \mathrm{MPa}$, respectively. The entire stress-strain curves and failure mode of tested samples are shown in Fig. 2. It is evident that the failure mode is mainly shear mode and the failure strength is basically the same for different tested samples, except no. 52 sample.

While for the normal strain of all tested samples, we can see that the pre peak strain of tested samples show similar trend, however, post peak strain behavior of samples are

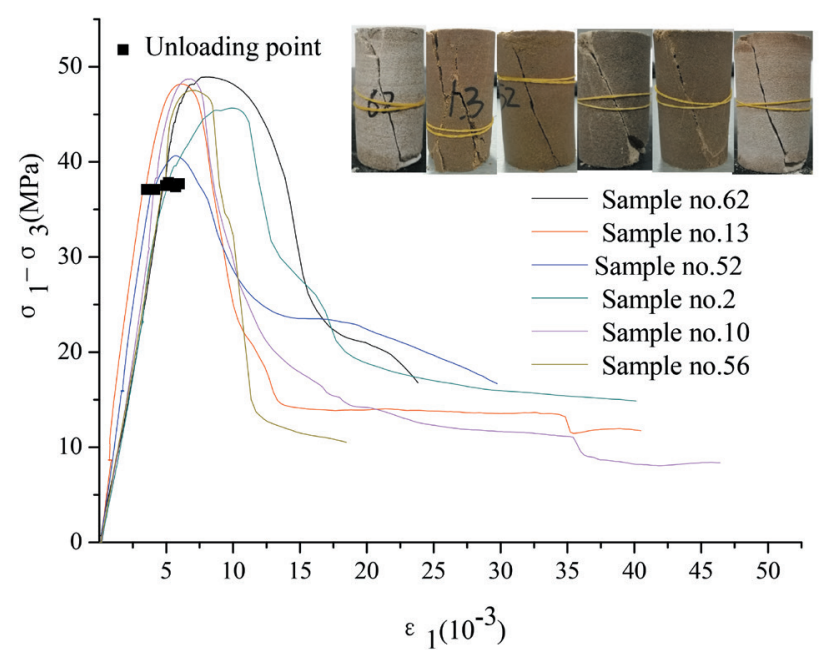

Fig. 2 Failure mode of unloading confining pressure test on specimens 
different, especially for no.2 and no.62 samples. As Adachi said in [25], the whole stress-strain curve can be divided into two stages: the strain hardening stage before peak strength and the strain softening stage after peak strength, and it can be seen that the major difference of tested samples occurs at strain softening stage, no.2 and no.62 samples undergoes larger strains before failure. Generally speaking, the difference of stress-strain curve is possibly formed due to the type of material, size of the sample and stiffness of the testing machines, while in our research, these reasons can be ignored, that is to say, we can presume that this difference is probably related to the particle size distribution, because when the peak strength is up to about $50 \mathrm{MPa}$, particles are apt to crush along with failure surface formation, which means the bigger the particle, the larger the strain before failure. This speculation will be verified in Section 3.3.

Then, the wet-dry cycles were carried out on rock samples with UF cracks by executing the following steps.

1. Samples were submerged into a vacuum-saturated pressurized apparatus to absorb water for $24 \mathrm{~h}$ and then oven-dried at $110{ }^{\circ} \mathrm{C}$ for $24 \mathrm{~h}$, which can effectively accelerate the wet-dry cycle process and simulate the water-weakening effect and rapid weathering under high temperature. Rock samples were subjected to a maximum of 9 cycles, which leaded to the entire disintegration of no.2 sample.

2. At the end of each drying process, the morphology features of unloading failure surface were tested by using ST400 device to figure out the effect of water on morphology structures of specimens. The scanning field of UF surface is shown in Fig. 3. During scanning process, the scanning parameters include:

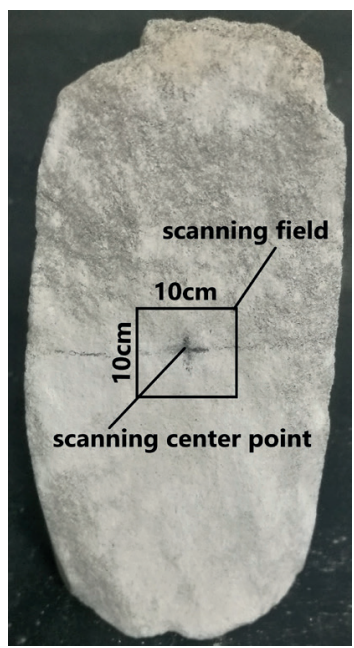

Fig. 3 Diagram of 3D scanning field step size $0.1 \mu \mathrm{m}$, speed $20 \mathrm{~mm} / \mathrm{s}$, scope in vertical direction $27 \mathrm{~mm}$, resolution of direction measurement $2 \mathrm{~nm}$, and ST400 device is shown in Fig. 4.

3. After undergoing each wet-dry cycle, sieve tests were performed in order to analyze the slake durability characteristics and the variation of grain-size distribution. First, the amount of clastic materials larger than $2 \mathrm{~mm}$ in size is commonly considered as the remaining sample [26-27], so the rock's mass loss ratio $\mathrm{P}$ can be adopted as a good indicator to describe the degree of disintegration and calculated as the following equation (Eq. (1)):

$$
P_{i}=\frac{m_{0}-m_{i}}{m_{0}} \times 100 \%,
$$

where $P_{i}$ is the rock's mass ratio of cumulative loss of dry rock mass after each wet-dry cycle to the original rock mass, $m_{0}$ is the original dry rock mass, and $m_{i}$ is the dry rock mass after each wet-dry cycle.

When the range of particle size is less than $2 \mathrm{~mm}$, the sieve sizes of $2 \mathrm{~mm}, 1 \mathrm{~mm}, 0.5 \mathrm{~mm}, 0.25 \mathrm{~mm}$, $0.1 \mathrm{~mm}$ and 0.075 were chosen to describe the variation of grain-size distribution for determining the particle size uniformity of tested samples, which is useful data to evaluate the effect of grain contacts on the physical disintegration characteristic of rock samples [28-29]. In this study, all the particle contents of grain-size less than $2 \mathrm{~mm}$ can be obtained after 9 wetdry cycles, they are named as $z_{1}, z_{0.5}, z_{0.25}, z_{0.1}$ and $z_{0.075}$, which indicate that the particle size ranges from $1 \mathrm{~mm}$

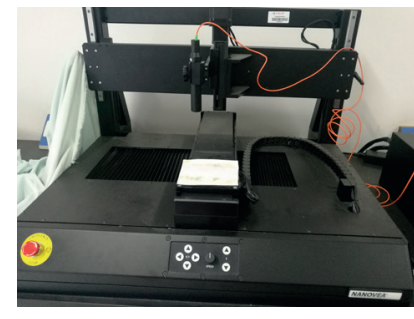

(a)

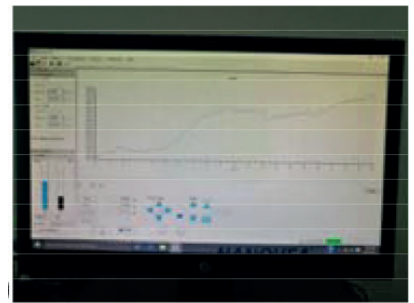

(b)

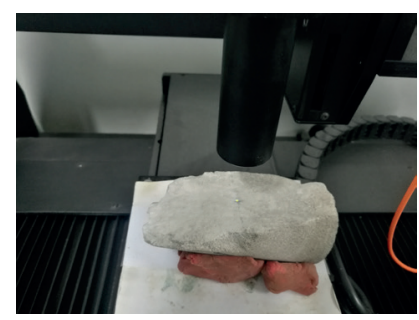

(c)

Fig. 4 ST400 device: (a) scanning platform, (b) software interface, (c) sample fixation 
to $2 \mathrm{~mm}, 0.5 \mathrm{~mm}$ to $1 \mathrm{~mm}, 0.25 \mathrm{~mm}$ to $0.5 \mathrm{~mm}, 0.1 \mathrm{~mm}$ to $0.25 \mathrm{~mm}$ and $0.075 \mathrm{~mm}$ to $0.1 \mathrm{~mm}$, respectively. Finally, the RMS of particle contents is adopted to describe the particle size uniformity of rock samples, which can be calculated as follows (Eq. (2)):

$$
R_{p}=\sqrt{\left(z_{1}^{2}+z_{0.5}^{2}+z_{0.25}^{2}+z_{0.1}^{2}+z_{0.075}^{2}\right) / 5}
$$

4. To analyze the effect of wet-dry cycles on microstructure of clay-bearing sandstone, all the remaining mass of tested samples were used to conduct SEM test at Geological and Environmental Institute of China University of Geosciences (Wuhan). The distribution of cracks and pores can be observed and porosities calculated as important factors reflecting the disintegration characteristics of rock samples.

\section{Experimental results}

\subsection{UF cracks development during wet-dry cycles}

In order to study the effect of the wet-dry cycles on the rock structure, visual observations were made after each cycle to obtain the UF cracks progress. It was found that the clay-bearing sandstone samples had the tendency to widen the UF cracks and finally disintegrate due to the wet-dry cycles. As shown in Figs. 5-10, the UF cracks rapidly widened and new cracks formed during the first wet-dry cycle (Figs. 5(b)-10(b)). All the rock samples progressively disintegrated (Figs. 5(c)-10(c)) as the number of wet-dry cycles increased.

It is noted that the nos. 2, 10 and 62 sample basically had an entire disintegration while the nos. 13, 52 and 56 sample only partly disintegrated after undergoing 9 wetdry cycles (Figs. 5(d)-10(d)). Thus, it enables us to classify specimens roughly into two groups: FD group, including the nos. 2, 10, 62 sample, and SD group, including the nos. 13, 52, 56 sample. To better understand the disintegration mechanism of two groups of rock samples, a mesoscopic 3D surface measurement was employed to analyze the morphology structure of specimens after each cycle. Moreover, the differences of particle size were obtained and SEM images were taken after the last wet-dry cycles for two groups of specimens. All of these have been illustrated in the following figures.

\subsection{Morphology of UF surface after each wet-dry cycle}

Observation of unloading failure surface after each wetdry cycle often help us have a better understanding of the influence of wet-dry cycles on the shape of those measured

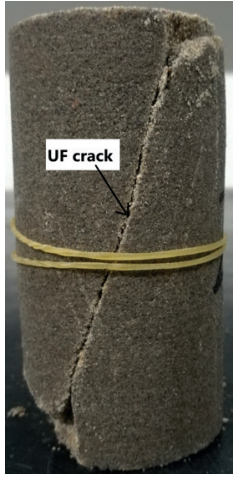

(a)

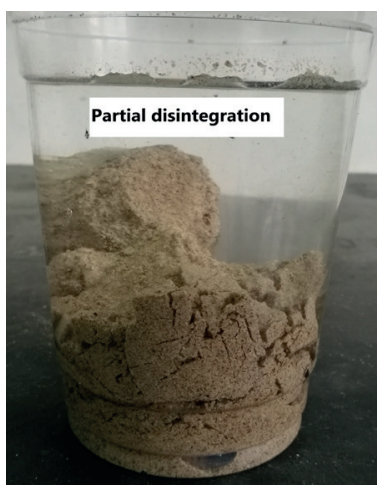

(c)

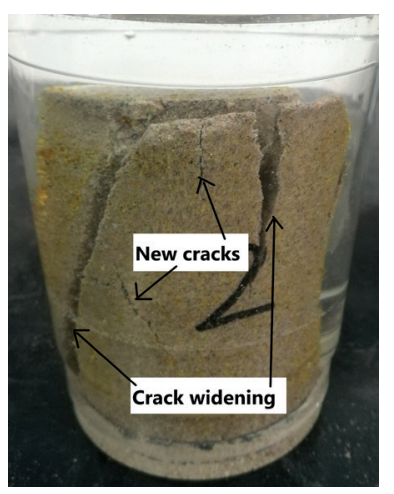

(b)

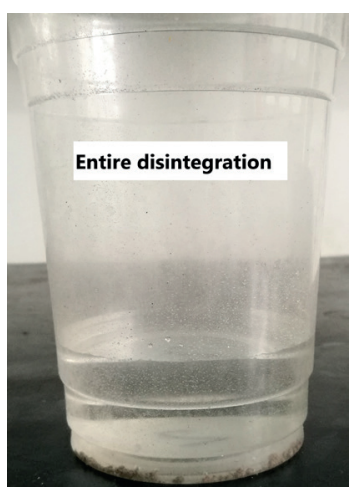

(d)
Fig. 5 Changes in the appearance of no. 2 sample after (a) 0 cycle, (b) 1 cycles, (c) 3 cycles, (d) 9 cycles

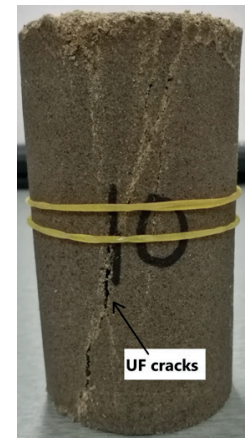

(a)

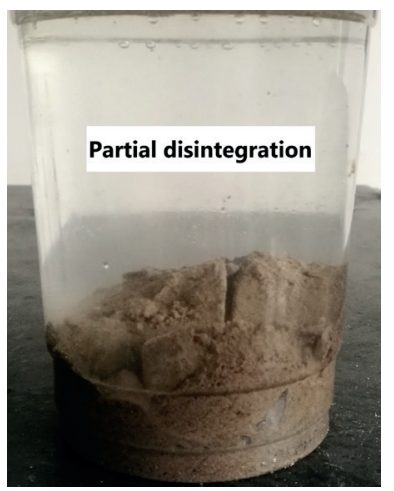

(c)

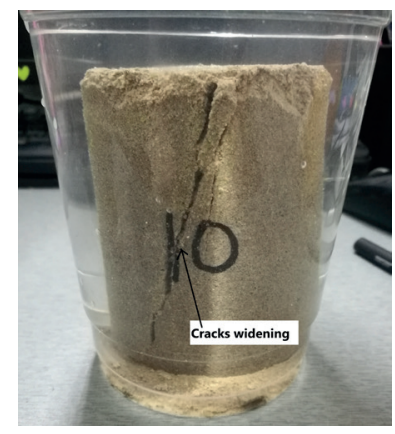

(b)

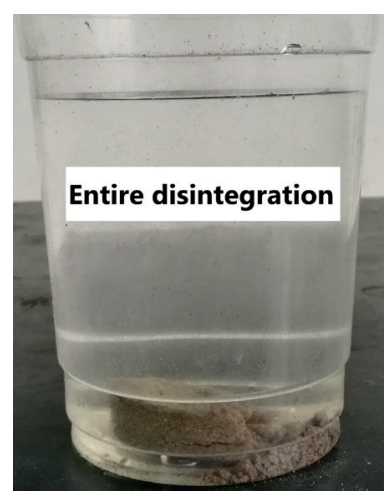

(d)
Fig. 6 Changes in the appearance of no.10 sample after (a) 0 cycle, (b) 1 cycles, (c) 3 cycles, (d) 9 cycles 


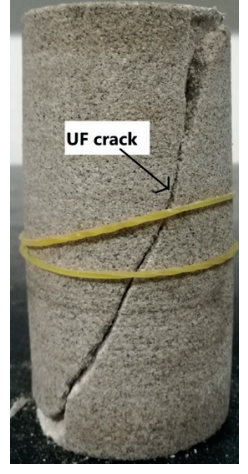

(a)

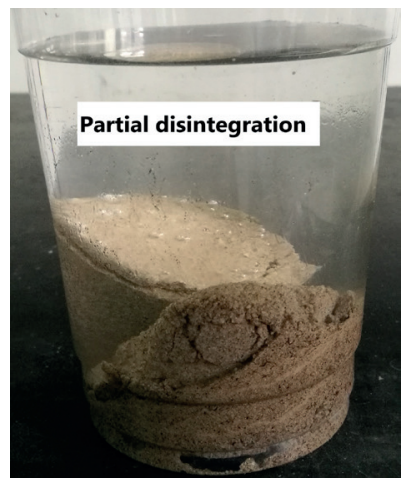

(c)

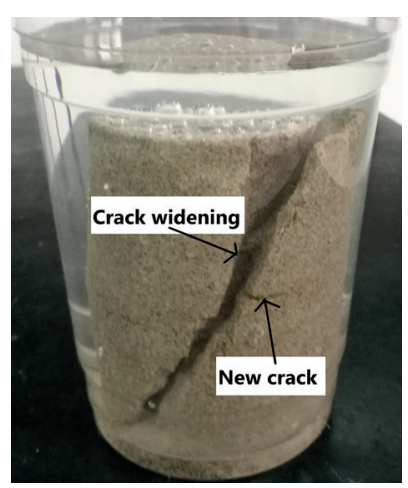

(b)

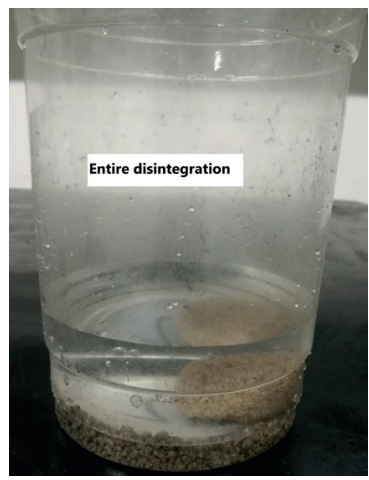

(d)

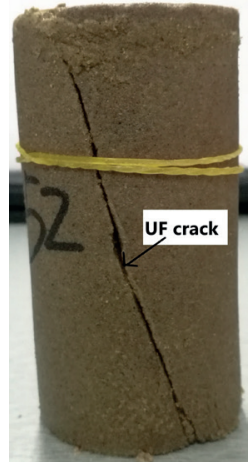

(a)

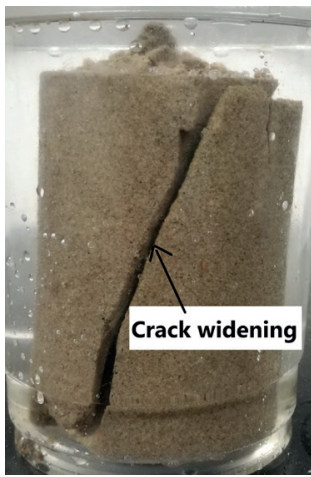

(c)

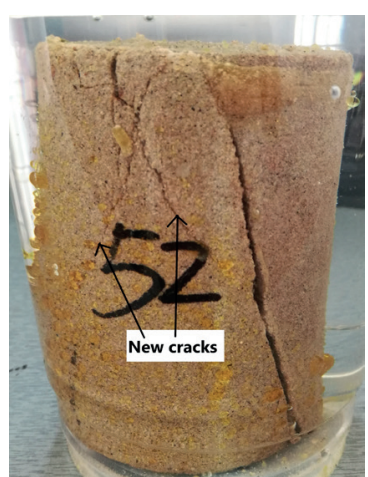

(b)

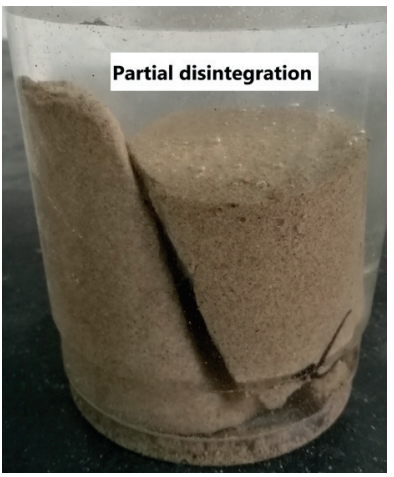

(d)
Fig. 7 Changes in the appearance of no.62 sample after (a) 0 cycle, (b) 1 cycles, (c) 3 cycles, (d) 9 cycles

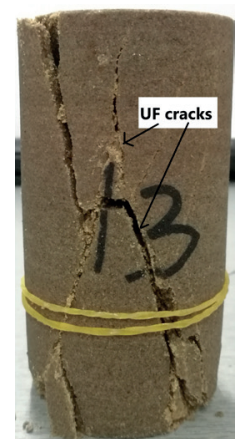

(a)

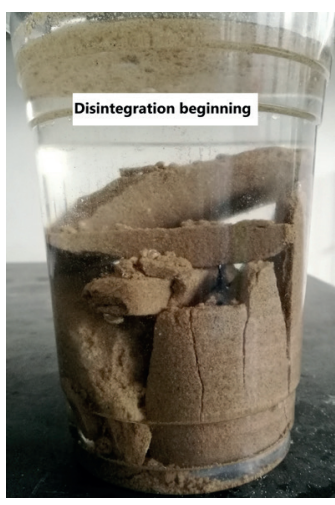

(c)

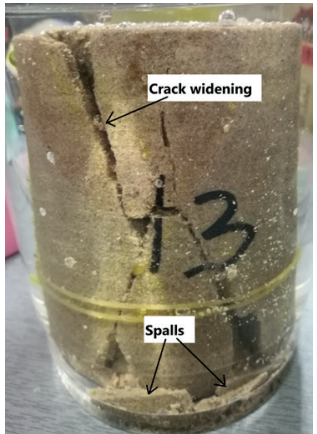

(b)

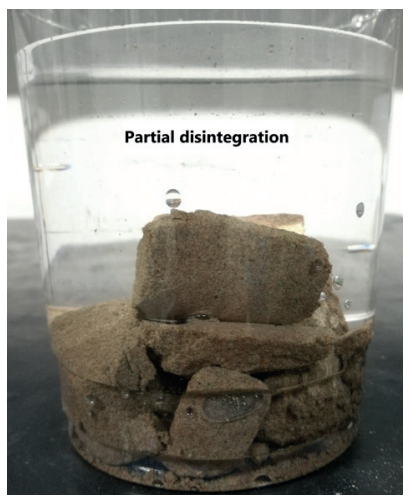

(d)
Fig. 8 Changes in the appearance of no.13 sample after (a) 0 cycle, (b) 1 cycles, (c) 3 cycles, (d) 9 cycles
Fig. 9 Changes in the appearance of no.52 sample after (a) 0 cycle, (b) 1 cycles, (c) 4 cycles, (d) 9 cycles

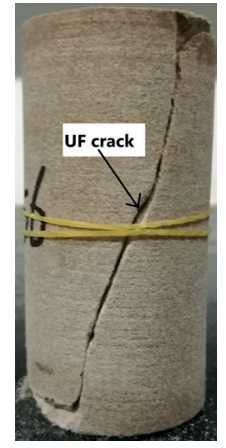

(a)

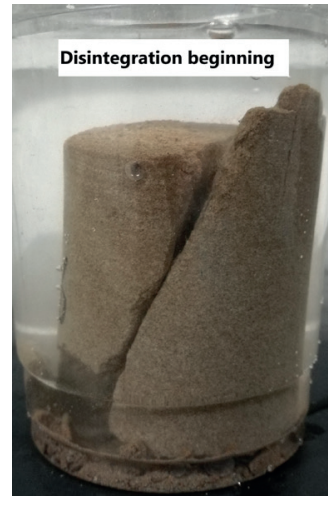

(c)

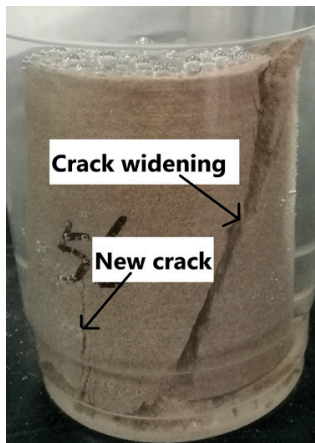

(b)

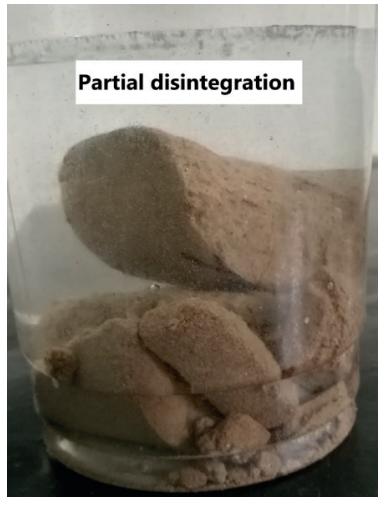

(d)
Fig. 10 Changes in the appearance of no.56 sample after (a) 0 cycle, (b) 1 cycles, (c) 4 cycles, (d) 9 cycles 
zones, which are mainly controlled by the roughness of the surface, including the size and the shape of the asperities. The sole objective of this research is to quantify the $3 \mathrm{D}$ roughness and anisotropy of unloading failure surface based on 3D surface measurement. Thus, the 3D morphology scanning tests are conducted in the measured field shown in Fig. 3, and it follows that a series of roughness parameters were obtained and used to describe the morphology of the surface.

In this paper, three roughness parameters [30-31] are chosen and calculated to illustrate the changes of roughness and anisotropy of surface after undergoing wet-dry cycles, including the RMS of height $S_{q}$, which indicates the distribution uniformity of surface; the kurtosis coefficient of height distribution $S_{k u}$, which reflect the degree of flatness of surface; and the texture aspect ratio of surface $S_{t r}$, which represent the degree of anisotropy of surface. It is noted that when the value of $S_{t r}$ is lower than 0.3 , we can believe that the surface is anisotropic, while larger than 0.3 , the surface is isotropic. The relationships between three parameters and the number of wet-dry cycle for no.10 sample from FD group and no.52 sample from SD group are shown in Figs. 11-13.

It can be seen from Fig. 11 that the height RMS $S_{q}$ of each of the two samples decreases as the number of wetdry cycle increases, but that of no.10 sample decreases more sharply after 4 wet-dry cycles, which means the water erosion has more remarkable effect on the morphology of surface of the sample from FD group. Fig. 12 indicates that during wet-dry cycles, the kurtosis coefficient of height distribution $S_{k u}$ of no. 52 sample decreases gently with the increasing of the number of wet-dry cycle, while for no. 10 sample, drastically decreases after 3 wet-dry cycles. It is noted from Fig. 13 that the morphology of surface of no.10 sample basically remains anisotropic during 9 wet-dry cycles, while for no. 52 sample, there is a transformation from isotropy to anisotropy after undergoing 9 wet-dry cycles.

Cao et al. [32] have also discussed the fractal dimension as a parameter describing the morphology features of rock surface, which indicates the value of fractal dimension of surface is basically larger by about 1 than that of profile. It is noted that for both fractal dimension of surface and of profile, no significant difference in the variation law of the two parameters for rock samples. Thus, the fractal dimension of UF surface is obtained in the current research to present its relationship with the number of wet-dry cycles for all tested samples, shown in Fig. 14. Similar with the

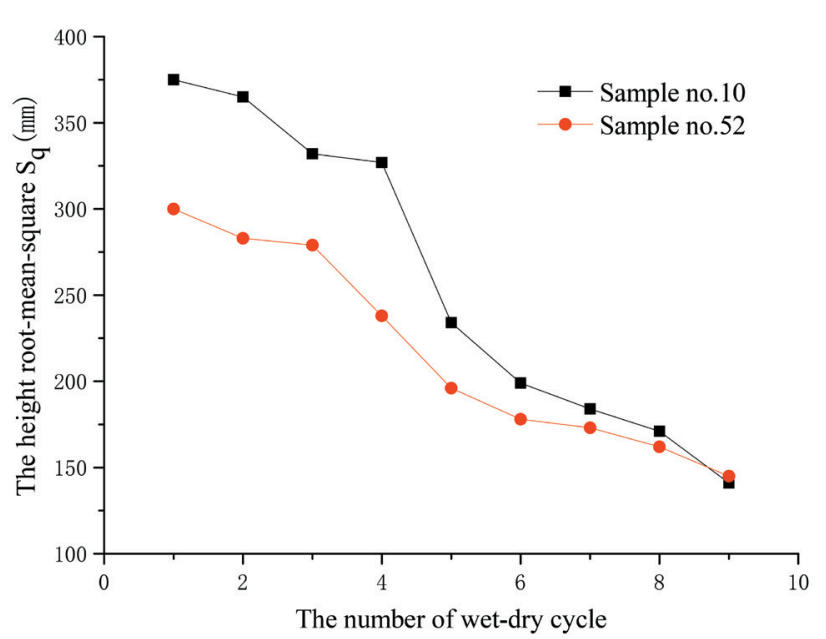

Fig. 11 Relationship between the height parameter Sq and the number of wet-dry cycle

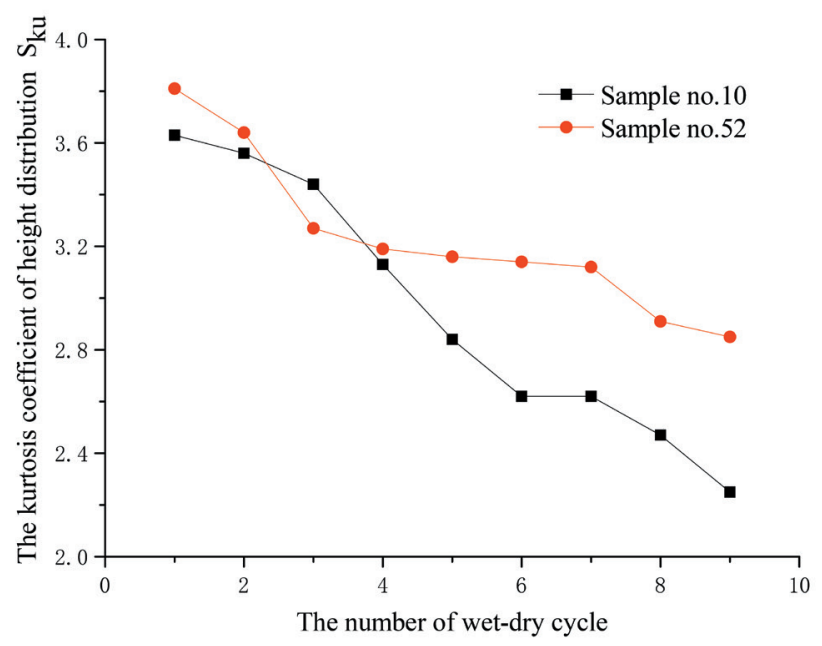

Fig. 12 Relationship between the kurtosis coefficient of height distribution Sku and the number of wet-dry cycle

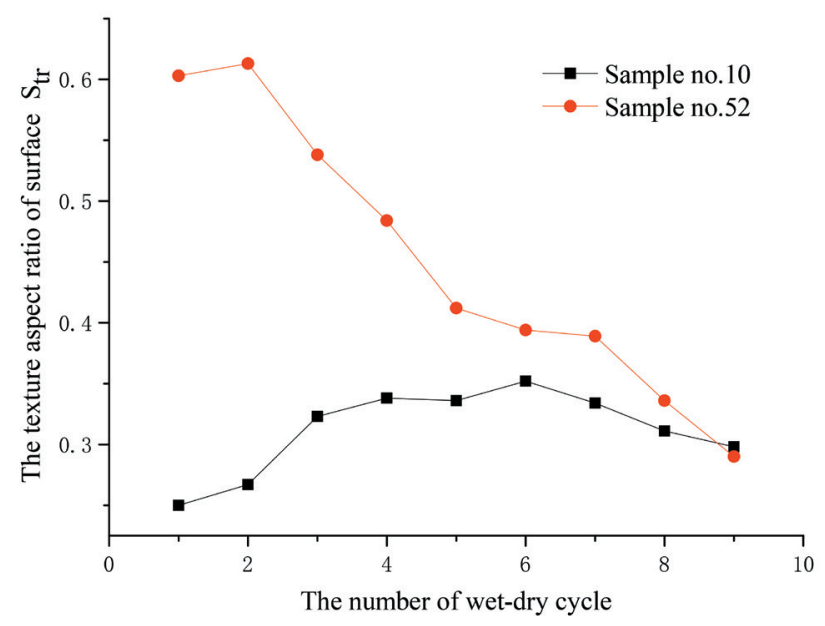

Fig. 13 Relationship between the texture aspect ratio of surface Str and the number of wet-dry cycle 


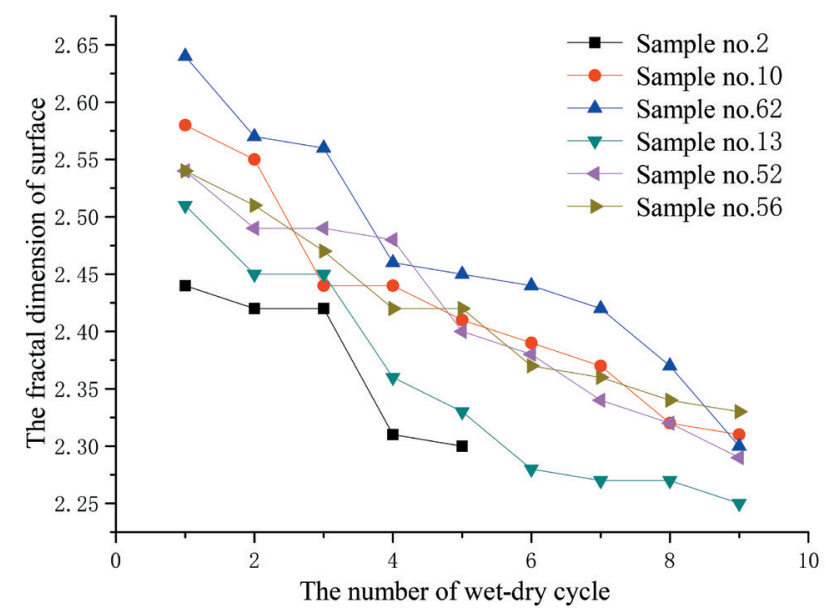

Fig. 14 Relationship between the fractal dimension of UF surface and the number of wet-dry cycle

aforementioned three parameters, the fractal dimension of UF surface also decreases as the increasing in the number of wet-dry cycle.

The data of all tested samples indicate that as the number of wet-dry cycles increased, the fractal dimension of UF surface sharply decreased, especially after the first two or three wet-dry cycles. For example, in the case of no. 2 sample, the fractal dimension of UF surface was as high as 2.44 , then decreased by about $5.32 \%$ after 3 wet-dry cycles, and finally entirely disintegrated after 5 wet-dry cycles. Such a dramatically change in the fractal dimension was closely associated with the water erosion on UF surface. However, there was no significant decrease for the fractal dimension in the last five or six wet-dry cycles, which means that the influence of water erosion on UF surface slows down in spite of an increased number of wet-dry cycles.

From the results presented above, we can find that for the tested clay-bearing sandstone samples during 9 wetdry cycles, the effect of water erosion on the morphology of UF surface is enormous, which makes the surface flatter and smoother, enhances the anisotropy of UF surface. Moreover, the wet-dry cycle has a greater influence on the samples from FD group than those from SD group.

\subsection{Grain-size distribution results}

After undergoing each wet-dry cycle, the rock mass ratio of cumulative loss of dry rock mass $P_{i}$ is calculated according to Eq. (1), and the relationship curves between $P_{i}$ and the number of wet-dry cycle are obtained and shown in Fig. 15. With the increasing number of wet-dry cycles, the percentage of disintegrated mass increased quickly from the first value of about $10 \%$ to the total for the samples,

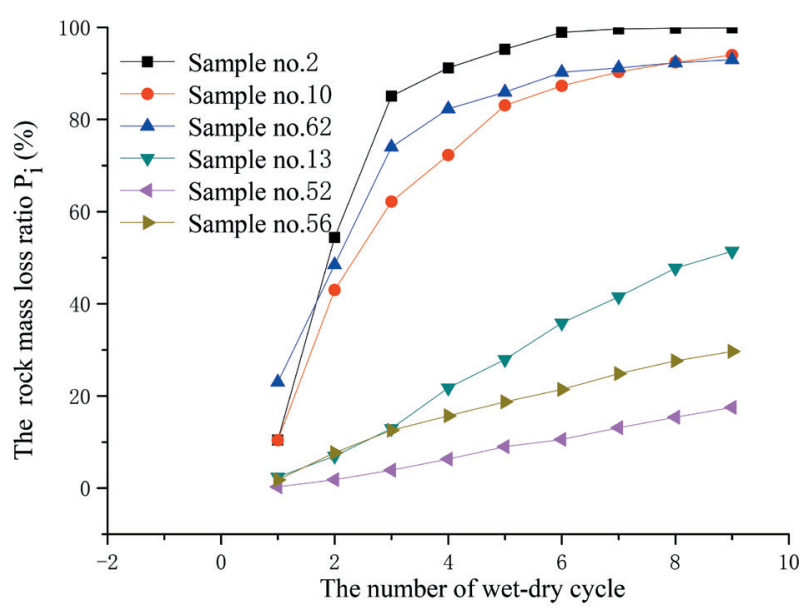

Fig. 15 Rock mass ratio of cumulative loss curves of clay-bearing sandstone samples under cyclic wet-dry conditions

numbered 2, 10, 62, from FD group, after undergoing 9 wet-dry cycles. Nevertheless, the percentage of the disintegrated mass for the samples, numbered 13, 52, 56, from SD group, increased slowly from $2.43 \%, 1.78 \%, 0.28 \%$ to $51.4 \%, 29.67 \%, 17.51 \%$, respectively. In view of this, all the tested samples is in a continuous state to disintegrate, and for the samples from FD group, the amount of clastic materials less than $2 \mathrm{~mm}$ changes relatively greatly only in the first three wet-dry cycles, and after then, the disintegrated mass slowly increased with the disintegrating process tending to be stable, finally, the disintegrated mass basically remains unchanged in the last three wetdry cycles. For the samples from SD group, the disintegrated mass linearly increases with the increasing number of wet-dry cycles.

After undergoing 9 wet-dry cycles, the particles of grain-size less than $2 \mathrm{~mm}$ for all tested samples have been sieved through different size of mesh drum and their particle contents are calculated to quantitatively evaluate the particle uniformity of specimens. The sieve results of no. 2 sample are shown in Fig. 16, and the particle contents and corresponding calculated RMS of particle contents $R_{p}$ as

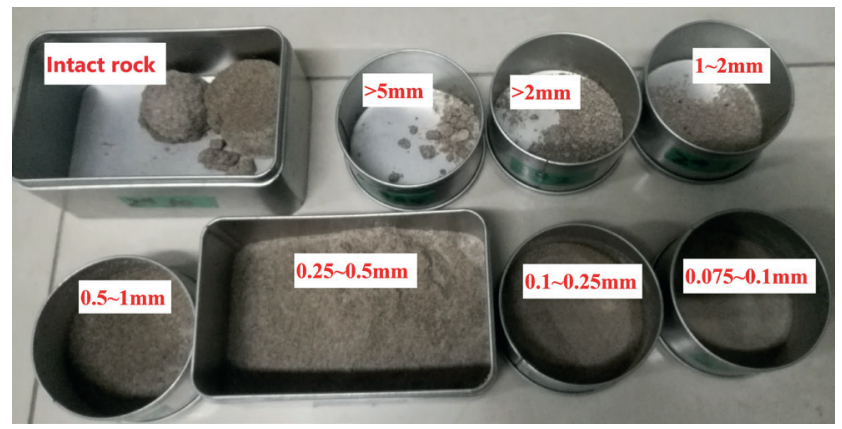

Fig. 16 Sieve results of typical tested samples 
Eq. (2) of all tested samples are in Table 4, respectively. To minimize the disturbance during sieving, the sieve procedure was done manually and any mechanical breakage by hand was prevented [29].

Based on the particle content results of all tested samples, it can be seen that for the samples from FD group, the particle contents with size $0.25 \sim 0.5 \mathrm{~mm}$ are far larger than those from SD group. The calculation results of RMS of particle contents for specimens from FD group vary from $23.01 \%$ to $28.46 \%$, also much greater than those from SD group, from $3.25 \%$ to $10.97 \%$ respectively. Therefore, the parameter, RMS of particle contents, is a good indicator to describe the particle uniformity of rock samples, which indicates the degree of particle uniformity of rock mass decreases with the increasing of RMS of particle contents.

As suggested by Lan [33], the size and number of rock pores (Fig. 17) between particles tend to increase as the particle uniformity decreases, here, it is to say that the larger the RMS of particle contents becomes, the more and larger the rock pores are. The disintegration mechanism of rock samples during wet-dry cycles is also sensitive to particle uniformity due to water [34-35]. As the rock becomes saturated, the water flows into the rock through pore structures and dissolves part of the clay mineral components of clay-bearing sandstone, reducing the grain cementation, which leads to a decrease of the bearing area and then a decrease in bearing intensity $[12,36]$.

Table 4 Grain composition and calculated RMS of all tested samples

\begin{tabular}{lcccccc}
\hline $\begin{array}{l}\text { Particle Sample no. } \\
\text { contents (\%) }\end{array}$ & 2 & 62 & 10 & 13 & 56 & 52 \\
\hline $1-2 \mathrm{~mm}$ & 4.19 & 8.64 & 2.41 & 3.31 & 2.67 & 1.59 \\
$0.5-1 \mathrm{~mm}$ & 16.52 & 15.34 & 12.45 & 7.29 & 4.33 & 2.24 \\
$0.25-0.5 \mathrm{~mm}$ & 60.19 & 50.39 & 45.86 & 20.81 & 7.85 & 5.90 \\
$0.1-0.25 \mathrm{~mm}$ & 11.38 & 12.84 & 19.48 & 10.21 & 11.80 & 3.23 \\
$0.075-0.1 \mathrm{~mm}$ & 2.54 & 4.37 & 2.03 & 0.77 & 3.09 & 0.32 \\
$\begin{array}{l}\text { The RMS of particle } \\
\text { contents }\left(R_{p}\right)\end{array}$ & 28.46 & 24.63 & 23.01 & 10.97 & 6.87 & 3.25 \\
\hline
\end{tabular}

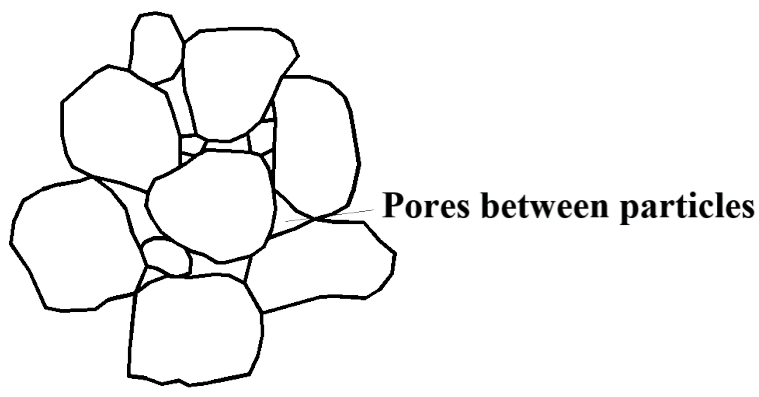

Fig. 17 Microstructural diagram of rock particle contact

\subsection{SEM image analysis and porosity calculation}

We conducted a microscopic observation of the SEM images of tested samples after 9 wet-dry cycles. Considering that the main purpose of this research is to compare the difference of pore structure of rock samples from different groups, Fig. 18 presents the SEM images of the tested pieces of two groups after undergoing 9 wet-dry cycles (the SEM images of 500 times magnification are listed, and that of no. 2 sample is not obtained because of its entire disintegration after 9 wet-dry cycles). The SEM characteristics and structures of the tested samples mainly included pores, cracks, mineral particles and fresh surface due to the absorption and desorption of water during wet-dry cycles. As Fig. 18 shows, the size, shape and distribution of pores and cracks of rock samples from FD group are obviously more than that of rock samples from SD group, the microstructures of rock samples from FD group are muddy and loose, while rock samples from SD group is neat and dense with some quartz mineral particles, which suggests that the microstructural features have significant differences between the samples from FD group and those from SD group.

To further quantitatively analyze the pore features of UF surface after undergoing wet-dry cycles, the 2D average porosity variation curves of all tested samples under different times magnification are obtained by the method of [37],

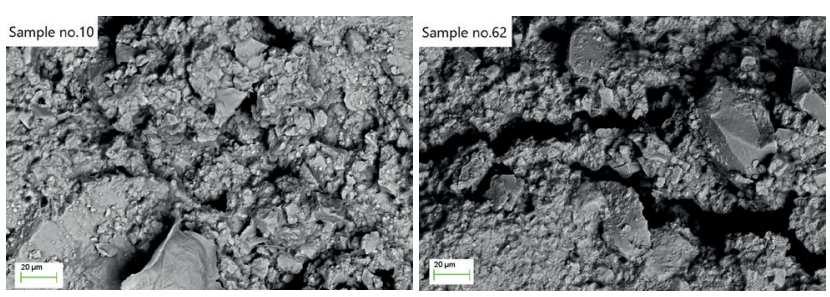

(a)
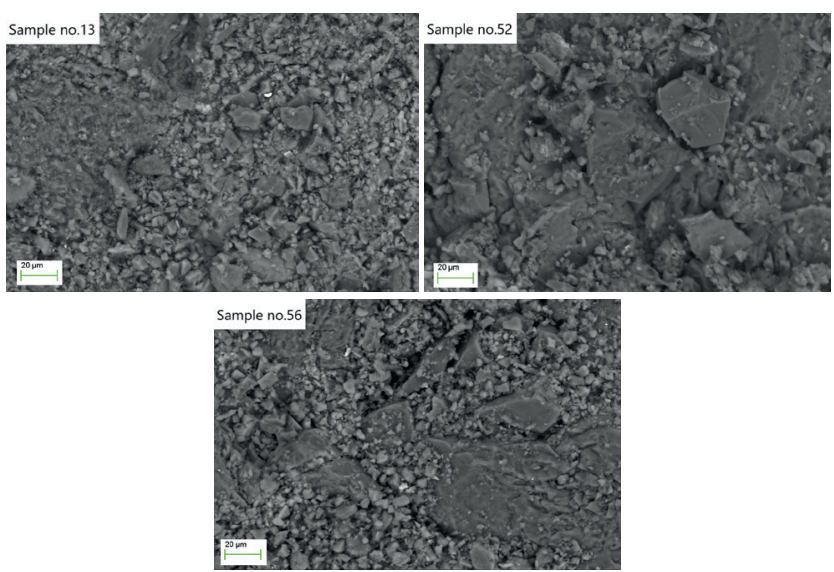

(b)

Fig. 18 SEM images of samples after 9 wet-dry cycles: (a) samples from FD group, (b) samples from SD group 
and shown in Fig. 19. This figure illustrates that the 2D average porosity of UF surface is mainly subject to linear increasing as the RMS of particle contents increases accordingly, which indicates that the microstructure of rock samples from FD group is looser and porous than those from SD group after undergoing 9 wet-dry cycles.

These results about element component, UF cracks, morphology of surface, particle uniformity and microstructure feature together imply that the sensitivity of disintegration to wet-dry cycles differs for the various rock properties. Thus, the disintegration mechanism of clay-bearing sandstone will be comprehensively discussed in the following part.

\section{Discussions}

Previous studies can reveal a few disintegration characteristics of clay-bearing sandstone during wet-dry cycles:

1. One of the purposes of this test is to assess the influence of wet-dry cycles on rock mass in association with engineering activities. Such activities may include slope and underground excavation, which commonly lead to the UF cracks. It is found in this research that the rock breakdown usually starts due to physical factors such as the existing UF cracks. The wetting stage can cause UF cracks widening and new cracks appearing as a result of the sample expanding during absorption of water, while it is impossible for samples to return to its original dimensions during drying stage [38]. Moreover, all tested samples are distinctly divided into two groups: FD and SD group according to the degree and speed of disintegration.

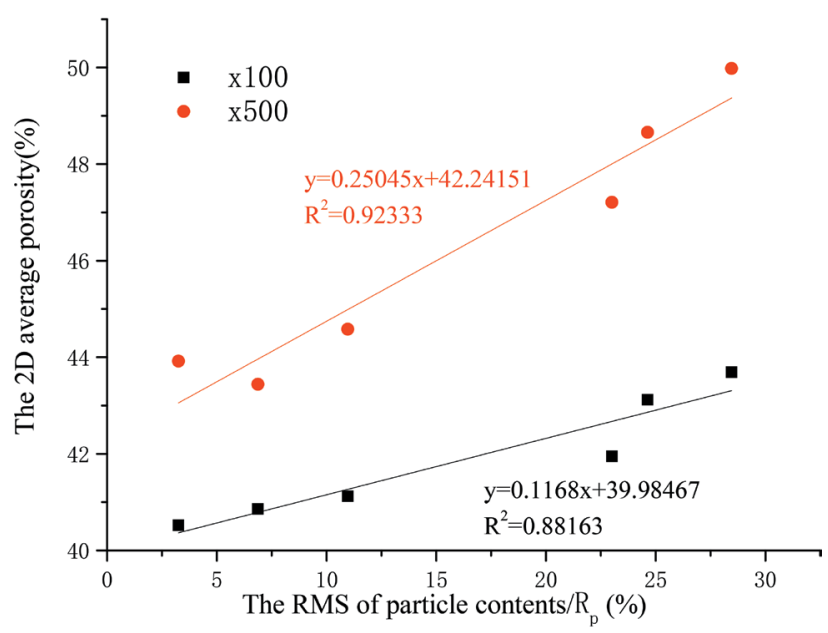

Fig. 19 Variation law of 2D average porosity with RMS of particle contents under different times magnifications
2. Morphology analysis suggests that the changes in moisture have an important effect on UF surface. The fractal dimension of UF surface drastically decreases in first two or three wet-dry cycles, then tends to slowly decrease with an increased number of wet-dry cycles. In terms of two groups of rock samples, the samples from FD group are more sensitive to water erosion by assessing the three parameters $S_{q}, S_{k u}$ and $S_{t r}$, which depends on the permeability, porosity and mineralogy of the rock.

3. The degree and speed of clay-bearing sandstone disintegration are subjected to the essential factor: particle uniformity in the periodic water-rock interaction. As the rock becomes more saturated, the water flows into the rock samples through pore structures and dissolves some of the mineral components, causing a reduction of capillary tension at grain contacts [12]. For the samples from FD group, a larger RMS of particle contents indicates a lower particle uniformity, which contributes to an increase in the number and size of pore throats and pores, increasing the porosity. The larger proportion of void space of rock samples from FD group causes a decrease in the bearing area and then a decrease in bearing intensity, facilitate rock dilatancy, which is required for rock deterioration and disintegration. Additionally, it can be verified that the variation of porosity has negative correlation with the particle uniformity through the SEM experimental analysis, which indicates that the lower the particle uniformity, the higher the porosity.

As many researchers suggested [39-40], clay mineral contents and the development of initial crack during wetdry cycles may have major influences on the deterioration characteristics and disintegration mechanism. However, we found that the clay mineral contents of all tested sample are basically similar in this research, and the UF crack have only a minor effect on the disintegration mechanism. This may be due to the fact that the degree and speed of rock disintegration is closely associated with the rock pores and the loss of cohesion between particles. Thus, for clay-bearing sandstone in the current research, the particle uniformity of rock seems to play an important control over the slake-durability of the rock samples.

\section{Conclusions}

The deterioration characteristics and disintegration mechanism of clay-bearing sandstone with UF cracks were investigated by surface morphology measurement, sieve 
test and SEM under cyclic wet-dry conditions. Based on the test results, the following conclusions can be drawn from this research:

1. Wet-dry cycles can widen the existing UF cracks to a level which mainly due to the dissolved clay mineral component. Besides, Wet-dry cycles can also cause the new crack formation, which was promoted through the weakening of intergranular bonds caused by the changes in moisture. However, the degree of disintegration for clay-bearing sandstone has little relationship with the development of cracks.

2. Surface morphology measurement on the tested rock samples indicates that the fractal dimension of UF surface decreases gradually under the cyclic wetdry conditions. The other three parameters also vary with the increase of number of wet-dry cycles, especially sensitive to the rock samples from FD group. The fact presents that the surface of the rock sample gets smooth and flat, but anisotropic after undergoing wet-dry cycles.

3. Particle-size analysis of the tested samples indicates that with the increasing number of wet-dry cycles, the contents of the disintegrated mass increases gradually, for the rock samples from SD group, but for the rock samples from FD group, especially with obvious increment in the first three wet-dry cycles and inconspicuous increment in the following cycles. Moreover, the parameter of RMS can effectively describe the particle uniformity of rock samples, which play a key role in a relatively rapid and entire disintegration of rock samples from FD group.

\section{References}

[1] Wang, Y., Li, J., Jiang, Q., Huang Y., Li, X. "Study on Spatial Variation of Shear Mechanical Properties of Soil-rock Mixture", Periodica Polytechnica Civil Engineering, 63(4), pp. 1080-1091, 2019.

https://doi.org/10.3311/PPci.14769

[2] Jiang, Q., Li, J., Luo, Z., Xu, X., Assefa, E., Deng, H. "Study on the Time-lag Failure of Sandstone with Different Degrees of Unloading Damage", Periodica Polytechnica Civil Engineering, 63(1), pp. 206-214, 2019.

https://doi.org/10.3311/PPci.13260

[3] Jiang, Q., Li, J., Wang, Y., Luo, Z., Li, T., Zhang, H., Assefa, E., Deng, H. "New Method for Determination of Residual Strength Parameters and Critical Damage Value", Periodica Polytechnica Civil Engineering, 63(2), pp. 569-576, 2019.

https://doi.org/10.3311/PPci.13817
4. After undergoing nine wet-dry cycles, the SEM results of two groups of tested samples show that the density and pore distribution of the rock surface is significantly different, that is to say, the microstructural feature of samples has closed link with the degree of disintegration. Furthermore, the quantitative variation is analyzed by the calculation of average plane porosity, which is consistent with the variation law of the parameter of RMS of particle contents, verifying the major effect of the particle uniformity and microstructural features on the disintegration mechanism for clay-bearing sandstone.

\section{Acknowledgement}

This work was supported by Key Laboratory of Geological Hazards on Three Gorges Reservoir Area (China Three Gorges University), Ministry of Education open fund project (No.2018KDZ14), the Natural Science Foundation of Hubei Province of China (No.2017CFB605), the National Natural Science Foundation of China (Nos.51309142, 51439003).

\section{Notation \\ UF cracks $=\quad$ Unloading Failure cracks \\ UF surface $=$ Unloading Failure surface \\ FD group $=\quad$ Fast Disintegration group \\ $\mathrm{SD}$ group $=\quad$ Slow Disintegration group \\ RMS $=\quad$ Root Mean Square}

[4] Li, D., Sun, Z., Xie, T., Li, X., Ranjith, P. G. "Energy evolution characteristics of hard rock during triaxial failure with different loading and unloading paths", Engineering Geology, 228, pp. 270$281,2017$. https://doi.org/10.1016/j.enggeo.2017.08.006

[5] Liang, Y., Li, Q., Gu, Y., Zou, Q. "Mechanical and acoustic emission characteristics of rock: Effect of loading and unloading confining pressure at the postpeak stage", Journal of Natural Gas Science and Engineering, 44, pp. 54-64, 2017. https://doi.org/10.1016/j.jngse.2017.04.012

[6] Seifabad, M. C., Sadrnejad, S. A., Ebrahimi, D. "A Study of Swelling Behaviour in a Tunnel Using Finite Element Methods", Periodica Polytechnica Civil Engineering, 59(2), pp. 103-107, 2015.

https://doi.org/10.3311/PPci.7538 
[7] Zhang, Z., Jiang, Q., Zhou, C., Liu, X. "Strength and failure characteristics of Jurassic Red-Bed sandstone under cyclic wettingdrying conditions", Geophysical Journal International, 198(2), pp. 1034-1044, 2014

https://doi.org/10.1093/gji/ggu181

[8] Gökceoğlu, C., Ulusay, R., Sönmez, H. "Factors affecting the durability of selected weak and clay-bearing rocks from Turkey, with particular emphasis on the influence of the number of drying and wetting cycles", Engineering Geology, 57(3-4), pp. 215-237, 2000. https://doi.org/10.1016/S0013-7952(00)00031-4

[9] Dhakal, G., Yoneda, T., Kato, M., Kaneko, K. "Slake durability and mineralogical properties of some pyroclastic and sedimentary rocks", Engineering Geology, 65(1), pp. 31-45, 2002.

https://doi.org/10.1016/S0013-7952(01)00101-6

[10] Liu, X.-R., Fu, Y., Wang, Y.-X., Huang, L.-W., Qin, X.-Y. "Stability of reservoir bank slope under water-rock interaction", Rock and Soil Mechanics, 30(3), pp. 613-616, 2009.(in Chinese) https://doi.org/10.16285/j.rsm.2009.03.018

[11] Luo, Z., Li, J., Wang L., Assefa, E., Deng, H. "Study on the Creep Characteristics of Sandstone under Coupled Stress-water Pressure", Periodica Polytechnica Civil Engineering, 63(4), pp. 1038-1051, 2019 https://doi.org/10.3311/PPci.14706

[12] Deng, H. F., Zhou, M. L., Li, J. L., Sun, X. S., Huang, Y. L. "Creep degradation mechanism by water-rock interaction in the red-layer soft rock", Arabian Journal of Geosciences, 9, pp. 601-612, 2016. https://doi.org/10.1007/s12517-016-2604-6

[13] Hua, W., Dong, S., Peng, F., Li, K., Wang, Q. "Experimental investigation on the effect of wetting-drying cycles on mixed mode fracture toughness of sandstone", International Journal of Rock Mechanics and Mining Sciences, 93, pp. 242-249, 2017. https://doi.org/10.1016/j.ijrmms.2017.01.017

[14] Gautam, T. P., Shakoor, A. "Comparing the slaking of clay-bearing rocks under laboratory conditions to slaking under natural climatic conditions", Rock Mechanics and Rock Engineering, 49, pp. 19-31, 2016.

https://doi.org/10.1007/s00603-015-0729-7

[15] Folk, R. L., Ward, W. C. "Brazos River bar: a study in the significance of grain size parameters", Journal of Sedimentary Research, 27(1), pp. 3-26, 1957.

https://doi.org/10.1306/74D70646-2B21-11D7-8648000102C1865D

[16] Erguler, Z. A., Shakoor, A. "Quantfication of fragment size distribution of clay-bearing rocks after slake durability testing", Environmental and Engineering Geoscience, 15(2), pp. 81-89, 2009.

https://doi.org/10.2113/gseegeosci.15.2.81

[17] Tavanaei, A., Salehi, S. "Pore, throat, and grain detection for rock SEM images using digital watershed image segmentation algorithm", Journal of Porous Media, 18(5), pp. 507-518, 2015. https://doi.org/10.1615/JPorMedia.v18.i5.40

[18] Yao, H.-Y., Zhu, D.-Y., Zhou, Y.-X., Liu, X.-T. "Real-time observation and analysis of fracturing process of sandstone under cyclic drying and wetting", Rock and Soil Mechanics, 34(2), pp. 331-336, 2013. (in Chinese) https://doi.org/10.16285/j.rsm.2013.02.012
[19] Xu, S.-M., Wu, Z.-J., Zhao, W.-C., Zhao, T. "Study of the microscopic Pores of Structured loess based on Matlab and IPP", China Earthquake Engineerimg Journal, 39(1), pp. 80-87, 2017. (in Chinese) https://doi.org/10.3969/j.issn.1000-0844.2017.01.0080

[20] Wang, L. L., Bornert, M., Héripré, E., Yang, D. S., Chanchole, S. "Irreversible deformation and damage in argillaceous rocks induced by wetting/drying", Journal of Applied Geophysics, 107, pp. 108-118, 2014. https://doi.org/10.1016/j.jappgeo.2014.05.015

[21] Liu, R., Li, B., Jiang, Y. "Critical hydraulic gradient for nonlinear flow through rock fracture networks: The roles of aperture, surface roughness, and number of intersections", Advances in Water Resources, 88, pp. 53-65, 2016. https://doi.org/10.1016/j.advwatres.2015.12.002

[22] Ma, C., Li, H., Niu, Y. "Experimental study on damage failure mechanical characteristics and crack evolution of water-bearing surrounding rock", Environmental Earth Sciences, 77, 2018. https://doi.org/10.1007/s12665-017-7209-1

[23] Gholamereza, K., Yasin, A. "Influence of wet-dry, freeze-thaw, and heat-cool cycles on the physical and mechanical properties of Upper Red sandstones in central Iran", Bulletin of Engineering Geology and the Environmental, 74(84), pp. 1287-1300, 2019. https://oi.org/10.1007/s10064-014-0691-8

[24] Zhao, Y., Ren, S., Jiang, D., Liu, R., Wu, J., Jiang, X. "Influence of wetting-drying cycles on the pore structure and mechanical properties of mudstone from Simian Mountain", Construction and Building Materials, 191, pp. 923-931, 2018. https://doi.org/10.1016/j.conbuildmat.2018.10.069

[25] Adachi, T., Oka, F. "An elasto-plastic constitutive model for soft rock with strain softening", International Journal, for Numerical and Analytical Methods in Geomechanics, 19(4), pp. 233-247, 1995. https://doi.org/10.1002/nag.1610190402

[26] Wudao, X., Liu, H., Wang, G. "Laboratory experimental study of slaking characteristics of red-bed soft rock", Chinese Journal of Rock Mechanics and Engineering, 29(2), pp. 4173-4179, 2010. Available at: http://qikan.cqvip.com/Qikan/Article/Detail?id= 35616605 [Accessed: 08 October 2019] (in Chinese)

[27] Zhang, D., Chen, A., Liu, G. "Laboratory investigation of disintegration characteristics of purple mudstone under different hydrothermal conditions", Journal of Mountain Science, 9, pp. 127-136, 2012 .

https://doi.org/10.1007/s11629-012-2204-1

[28] Dick, J. C., Shakoor, A. "Lithologic controls of mud rock durability", Quarterly Journal of Engineering Geology and Hydrogeology, 25(1), pp. 31-46, 1992. https://doi.org/10.1144/GSL.QJEG.1992.025.01.03

[29] Gautam, T. P., Shakoor, A. "Slaking behavior of clay-bearing rocks during a one-year exposure to natural climatic conditions", Engineering Geology, 166, pp. 17-25, 2013. https://doi.org/10.1016/j.enggeo.2013.08.003

[30] Chen, Y., Cao, P., Pu, C. Z., Liu, Y. K., Li, N. "Experimental Study on the Influence of Water-Rock Interaction on Rock Surface Micromorphology", Rock and Soil Mechanics, 31(11), pp. 34523458, 2010. (in Chinese) https://doi.org/10.16285/j.rsm.2010.11.052 
[31] Wang, Y., Ai, Q., Li, J.-L., Deng, H.-F. "Damage characteristics of sandstone under different influence factors and its unloading failure meso-morphology properties", Rock and Soil Mechanics, 40(4), pp. 1341-1350, 2019. (in Chinese)

https://doi.org/10.16285/j.rsm.2017.2310

[32] Cao, P., Jia, H.-Q., Liu, T.-Y., Pu, C.-Z., Fan, X. "Fractal analysis of three-dimensional topography characteristics of rock joint surface", Chinese Journal of Rock Mechanics and Engineering, 30(Suppl. 2), pp. 3839-3843, 2011. (in Chinese). Available at: http:// qikan.cqvip.com/Qikan/Article/Detail?id=44844652 [Accessed: 08 October 2019]

[33] Zhou, X., Liu, P., Lan, Z. "Experimental study on disintegration behavior of Granite residual soil", In: Geo-Hubei 2014 International Conference on Sustainable Civil Infrastructure, Yichang, China, 2014, pp. 98-104. (in Chinese) https://doi.org/10.1061/9780784478509.013

[34] Franklin, J. A., Chandra, R. "The slake-durability test", International Journal of Rock Mechanics and Mining Science \& Geomechanics Abstracts, 9(3), pp. 325-341, 1972. https://doi.org/10.1016/0148-9062(72)90001-0

[35] Crosta, G. "Slake-durability vs ultrasonic treatment for rock durability determinations", International Journal of Rock Mechanics and Mining Science, 35(6), pp. 815-824, 1998. https://doi.org/10.1016/S0148-9062(98)00006-0
[36] Cantón, Y., Solé-Benet, A., Queralt, I., Pini, R. "Weathering of a gypsum-calcareous mudstone under semi-arid environment at Tabernas, SE Spain: laboratory and field-based experimental approaches", CATENA, 44(2), pp. 111-132, 2001. https://doi.org/10.1016/S0341-8162(00)00153-3

[37] Wang, Y., Qiao, Q., Li, J. "The Effect of Initial Creep Damage on Unloading Failure Properties of Sandstone from Macro-mesoscopic Perspective", Periodica Polytechnica Civil Engineering, 63(4), pp. 1004-1015, 2019. https://doi.org/10.3311/PPci.14535

[38] Nepper-Christensen, P. "Shrinkage and Swelling of Rocks due to Moisture Movements", Bulletin of the Geological Society of Denmark, 15(4), pp. 548-555, 1965. [online] Available at: https://2dgf.dk/xpdf/bull-1964-15-4-548-555.pdf [Accessed: 08 October 2019]

[39] Moon, V. G., Beattie, A. G. "Textural and microstructural influences on the durability of Waikato Coal Measures mud rocks", Quarterly Journal of Engineering Geology and Hydrogeology, 28, pp. 303-312, 1995.

https://doi.org/10.1144/GSL.QJEGH.1995.028.P3.08

[40] Gratchev, I., Pathiranagei, S. V., Kim, D. H. "Strength properties of fresh and weathered rocks subjected to wetting-drying cycles", Geomechanics and Geophysics for Geo-Energy and GeoResources, 5, pp. 211-221, 2019.

https://doi.org/10.1007/s40948-019-00104-5 